\title{
Seismic reflection images of a near-axis melt sill within the lower crust at the Juan de Fuca Ridge
}

J. Pablo Canales ${ }^{1}$, Mladen R. Nedimović ${ }^{2,3}$, Graham M. Kent ${ }^{4}$, Suzanne M. Carbotte ${ }^{3}$, and Robert S. Detrick ${ }^{1}$

${ }^{1}$ Department of Geology and Geophysics, Woods Hole Oceanographic Institution, Woods Hole, Massachusetts 02543, USA. ${ }^{2}$ Department of Earth Sciences, Dalhousie University, Halifax, Nova Scotia B3H 4J1, Canada. ${ }^{3}$ Lamont-Doherty Earth Observatory of Columbia University, Palisades, New York 10964, USA. ${ }^{4}$ Scripps Institution of Oceanography, University of California San Diego, La Jolla, California 92093, USA.

The oceanic crust extends over two thirds of the Earth's solid surface and is generated along mid-ocean ridges from melts derived from the upwelling mantle ${ }^{1}$. The upper and mid crust are constructed by dyking and seafloor eruptions originating from magma accumulated in mid-crustal lenses at the spreading axis ${ }^{2-6}$, but the style of accretion of the lower oceanic crust is actively debated ${ }^{7}$. Models based on geological and petrological data from ophiolites propose that the lower oceanic crust is accreted from melt sills intruded at multiple levels between the Moho transition zone (MTZ) and the mid-crustal lens ${ }^{8-11}$, consistent with geophysical studies that suggest the presence of melt within the lower crust $^{12-16}$. However, seismic images of molten sills within the lower crust have been elusive. To date only seismic reflections from mid-crustal melt lenses ${ }^{2,17,18}$ and sills within the MTZ have been described ${ }^{19}$, suggesting that melt is efficiently transported through the lower crust. Here we report deep crustal seismic reflections off the southern Juan de Fuca Ridge that we interpret as originating from a molten sill presently accreting the lower oceanic crust. The sill sits 5-6 $\mathrm{km}$ beneath the seafloor and 850-900 $\mathrm{m}$ above the MTZ, and it is located $1.4-3.2 \mathrm{~km}$ off the 
spreading axis. Our results provide evidence for the existence of low permeability barriers to melt migration within the lower section of modern oceanic crust forming at intermediate-to-fast spreading rates, as inferred from ophiolite studies $^{9,10}$.

The Juan de Fuca Ridge (JdFR) is a mid-ocean ridge in the Northeast Pacific (Fig. 1) where spreading occurs at intermediate rates $\left(56 \mathrm{~mm} / \mathrm{yr}^{[20]}\right)$. The results presented here arise from a two-dimensional seismic reflection survey conducted in 2002 along the JdFR and its flanks ${ }^{19,21,22}$. This survey imaged the top of an axial magma chamber (AMC) beneath all JdFR segments at depths of $\sim 2-3 \mathrm{~km}^{[22]}$. Reflections from the crustmantle boundary (Moho) were observed throughout much of the survey at 2,080 \pm 100 ms crustal two-way traveltime (TWTT), as well as sub-Moho reflections interpreted as gabbro lenses and possibly melt accumulations ${ }^{19}$ (Fig. 1).

Along the Cleft segment of the JdFR (Fig. 1) the top of the AMC is $2.0-2.3 \mathrm{~km}$ $\operatorname{deep}^{21}$ (Fig. 2b, f), and Moho is imaged intermittently throughout the area ${ }^{21}$. Crustal traveltimes to Moho decrease away from the axis and decrease northward from $\sim 2,550$ $\mathrm{ms}$ at the south end to $\sim 2,300 \mathrm{~ms}$ at the north end ${ }^{21}$ (Fig. 2a and Supplementary Fig. $\mathrm{S} 1 \mathrm{a})$. The exception to these general trends is a pronounced $\sim 11-\mathrm{km}$-long area of anomalously large crustal traveltimes located $\sim 3-5 \mathrm{~km}$ east of the spreading axis (Supplementary Fig. S1a), suggesting local crustal thickening, elevated crustal temperatures, presence of melt above the Moho, or a combination of any of these factors.

At the southern end of this anomaly, profiles 75 and 40 (Fig. 1) show a reflection event at 2,000 ms below the seafloor (Fig. 2a, b, d, and h). This event is located 1.4-3.2 $\mathrm{km}$ to the east of the spreading axis, in 50-114 kyr-old crust ${ }^{20}$, extending $\sim 2.4 \mathrm{~km}$ and $\sim 1.8 \mathrm{~km}$ in the ridge-parallel and ridge-perpendicular directions, respectively. The 
reflection event must originate at depths of 5-6 km (for an average crustal velocity of 5$6 \mathrm{~km} \mathrm{~s}^{-1}$ above this reflector) from layering that is likely be at least $\sim 100$-m thick in order to be detected by our signal (which has a dominant frequency of $12 \mathrm{~Hz}$ and a dominant wavelength of 400-500 $\mathrm{m}$ at those depths). The origin of this event could be an anomalous Moho, a frozen sill of ultramafic material embedded in gabbros (such as a wehrlite intrusion $^{23}$ ), or a molten sill. Based on its amplitude variation with offset (AVO) response (Fig. 3) and on other considerations discussed below, we interpret this event as originating from a lower crustal melt lens (LCML).

The possibility that the reflection event is an anomalously shallow Moho seems unlikely because this implies abrupt crustal thinning by either a reduction in magma supply in a small area that is otherwise surrounded by large Moho traveltimes (Supplementary Fig. S1a), or by tectonic thinning or uplifting, for which there is no evidence in the seafloor morphology. Average crustal TWTT to Moho observed along Line 40 is 2,256 ms (Fig. 2a, c-e), which is $256 \mathrm{~ms}$ more than for the LCML event (Fig. 2d). In addition, a weak Moho event, which can be recognized in the pre-stack gathers at far offsets (Fig. 3b), appears to extend beneath the LCML (Fig. 2d). This indicates that the top of the LCML is located within the lower crust, about 850-900 m above the Moho (for a lower crustal velocity of $6.8 \mathrm{~km} \mathrm{~s}^{-1}$ ).

The LCML event displays a complex reflection pattern with two positive (black) peaks compared to one from the Moho reflection (Fig. 2d, g). This suggests that the LCML event was produced by a complex velocity structure (rather than a simple velocity increase/decrease) possibly associated with two or more sills or the roof and floor of a single sill. In this case the polarity of the reflection of the LCML may not be useful to discriminate between positive or negative impedance contrasts, as one would expect from the ideal case of a simple sill intrusion ${ }^{18}$. In a first-order approximation, both the Moho and a frozen ultramafic sill should have identical impedance contrasts 
because they both represent ultramafic material sitting below gabbros. Therefore, minor amplitude interference effects aside, the comparison of the AVO responses of Moho and LCML events (Fig. 3d-f) observed in pre-stack gathers (Fig. 3a, b) can help determine if the LCML corresponds to a positive of a negative velocity contrast. Figure $3 d-f$ shows that the $P$-wave reflecting off the LCML $\left(P_{L C M L} P\right)$ has higher amplitude than the Moho for offsets $<3 \mathrm{~km}$, and that the amplitude of the $P_{L C M L} P$ decays more rapidly between 3 and $5 \mathrm{~km}$ offset while Moho amplitude shows less variation across all offsets (Fig. 3f). This difference in AVO responses resembles the predicted variations with offset of reflection coefficients for $P$-waves reflecting off a low velocity molten sill and a highvelocity Moho or ultramafic sill (Fig. 3f), and suggests that the LCML reflection corresponds to a molten sill.

For a fully molten sill one expects to observe at far offsets significant converted $S$ wave energy reflecting off the LCML ${ }^{18}\left(P_{L C M L} S\right.$, Supplementary Fig. S3). We do not observe high-amplitude $S$-wave arrivals in the data, but we recognize a weak arrival at offsets larger than $\sim 4.5 \mathrm{~km}$ between $\sim 6.0-6.2 \mathrm{~s}$, where the $P_{L C M L} S$ is expected to be present (Fig. 3b, c). Although the weak amplitude of the $P_{L C M L} S$ is more consistent with a "mush" sill than a fully molten one (Supplementary Fig. S3), the observed AVO response of the $P_{L C M L} P$ event suggests a melt-rich sill (other factors such as attenuation may be affecting the strength of the $P_{L C M L} S$ event). However our data cannot distinguish between mush at the crystal scale and a set of molten sills smaller than the dominant wavelength of the seismic signal encased in solid cumulates.

The largest crustal TWTT to Moho at the southern edge of the LCML event is 2,508 ms, which is $252 \mathrm{~ms}$ more than the average crustal TWTT observed along Line 40. Assuming that this Moho travel time anomaly is entirely caused by thickening of the lower crust beneath the LCML, it implies a local thickness anomaly of $\sim 850-900 \mathrm{~m}$ (for a lower crustal velocity of $6.8 \mathrm{~km} \mathrm{~s}^{-1}$ ), placing the crust-mantle boundary $1,700-1800 \mathrm{~m}$ 
beneath the LCML. Alternatively, the Moho travel time anomaly could be due to a 45 $50 \%$ reduction in $P$-wave velocity, implying a completely molten lowermost crust regardless of how melt is distributed and interconnected ${ }^{24}$. These two scenarios are endmember possibilities; most likely the travel time anomaly below the LCML is due to both, presence of melt and local thickening of the lower crust.

Melt migration from the mantle to the crust is thought to be a process of focused porous flow ${ }^{25,26}$, although this may change at the MTZ as melts enter a conductively cooling regime and build up permeability barriers by crystallizing plagioclase, leading to the emplacement of melt sills within the MTZ ${ }^{11}$. In contrast, porous flow may not be the dominant mechanism of melt migration above the $\mathrm{MTZ}^{27}$, and lower crustal sills could be fed by focused flow along channels originating at the MTZ melt sills ${ }^{10,11}$. Several mechanisms have been proposed for the creation of permeability barriers that can allow the emplacement of melt sills at multiple levels within the lower crust, such as the presence of anorthosite bands, plagioclase-clinopyroxene-orthopyroxene saturation within crystallizing gabbros, or formation of low porosity cumulate gabbros after melt extraction $^{10}$. Our data cannot discriminate between these processes; however the observation that the LCML is emplaced a few kilometres off the spreading axis allows us to hypothesize that here, the melt sill could have formed at a permeability barrier associated with a contrasting thermal regime above it, in a similar manner to the emplacement of the axial mid-crustal melt lens ${ }^{28,29}$. The axial region of fast-spreading ridges is characterized by a $5-7-\mathrm{km}$-wide zone of low seismic velocities ${ }^{14}$. The lateral boundaries of this region are interpreted as steep isotherms controlled by the transition from shallow hydrothermal circulation at the ridge axis to deep-penetrating hydrothermal fluid pathways just a few kilometres off the spreading axis ${ }^{14}$. Thus we interpret that the off-axis deep melt sill imaged by our data represents a deep freezing horizon that roughly follows the boundaries of an axial low velocity zone. 
The imaged LCML is wider than the shallow AMC lens (Fig. 2f, h, 4). However its along-axis extent is much more limited than the AMC (Fig. 4b), which extends along tens of kilometres beneath the ridge ${ }^{21}$. The along-axis continuity of AMC lenses observed at many spreading centres implies that it is a relatively steady-state feature frequently replenished with magma from below. Therefore the limited spatial extent of the LCML, together with the absence of similarly sized lower crustal reflections in the only three-dimensional seismic reflection study of a fast-spreading ridge published to date $^{12}$, suggests that lower crustal melt sills are probably less frequently fed than the AMC lens, and/or that the LCML imaged in our data is uncommonly large.

The seafloor in the area where profiles 40 and 75 intersect is flatter, smoother, and has higher reflectivity than the surroundings (Supplementary Fig. S1b-d), suggesting younger terrain and repaving of the seafloor. Lava flows up to $4 \mathrm{~km}$ off-axis emanating from ridge-parallel faults and fissures have been identified along the Cleft segment and interpreted as erupting from the edges of the $\mathrm{AMC}$ lens ${ }^{30}$. In addition, the axial summit graben of Cleft segment is flanked by some small, young-looking near-axis seamounts with chemistry distinct from the axial lavas (Fig. 4a) ${ }^{30}$. Observations by submersible vehicles have also reported the presence of low-temperature hydrothermal venting $\sim 3.3$ $\mathrm{km}$ east of the spreading axis ${ }^{30}$ and $\sim 10 \mathrm{~km}$ to the south of the LCML (Fig. 1, 2a, 4a). Our discovery of lower crustal melt sills at similar distances from the spreading axis in the same area suggests that deep lower crustal melt lenses could also contribute to construction of the upper crust by off-axis seafloor eruptions, and provide heat for offaxis hydrothermal circulation.

Our data provide evidence for a molten sill presently accreting the lower oceanic crust at the JdFR. The location of the sill within 50-114 kyr-old crust suggests that a crustal column formed at this section of the JdFR represents magmatic accretion over a time period of at least 100 thousand years. Near-axis lower crustal reflections have 
been previously reported at the East Pacific Rise ${ }^{31}$. However, their along-axis extent has not been explored and they were not interpreted as melt sills ${ }^{31}$. Our results imply the existence of low permeability barriers to melt migration within the lower oceanic crust, in agreement with models based on observations at ophiolites ${ }^{9,10}$, and indicate that melt migration from the MTZ to the shallow AMC lens may not necessarily be as efficient as recently inferred from three-dimensional seismic reflection data ${ }^{12}$. Since the paleo-conditions under which crustal sections exposed at ophiolites were formed are in most cases difficult to determine, there is some ambiguity about the extent to which ophiolites are analogues to modern oceanic crust $^{32}$. Our results thus support the idea that some of the lower-crustal processes inferred from ophiolite settings do occur during the accretion of modern oceanic crust at intermediate-to-fast spreading rates. However the uniqueness and limited extent of the imaged LCML compared to the mid-crustal melt lens suggests that large lower crustal melt sills are rare and probably contribute a small fraction to the overall thickness of the lower crust, as suggested by numerical models and petrological constraints ${ }^{7,33}$.

\section{METHODS SUMMARY}

Data processing. Acquisition parameters are described in refs. ${ }^{19,21}$. Pre-stack processing consisted of $f$ - $k$ filtering, sorting into 80-fold common-midpoint (CMP) gathers, amplitude correction for spherical divergence, trace editing, band-pass filtering (2-7-20-40 Hz), velocity analysis and normal move-out (NMO) correction. After stacking, data were muted below first seafloor multiple, time migrated using stacking velocities, and muted above the seafloor reflection. CMP supergathers were constructed by sorting 30 consecutive CMP gathers into 5 -fold constant-offset gathers, partial stacking, and band-pass filtering (2-7-20-40 Hz). 
AVO analysis. Instantaneous amplitudes were calculated on CMP supergathers after NMO correction to flatten the seismic events and partial stacking of traces within $250-\mathrm{m}$ bins.

Forsyth, D. W., Geophysical constraints on mantle flow and melt migration beneath mid-ocean ridges. In Mantle flow and melt generation at mid-ocean ridges, edited by J. Phipps Morgan, D. K. Blackman, and J. M. Sinton (AGU, Washington, D. C., 1992), Vol. 71, pp. 1-65.

2 Detrick, R. S. et al., Multi-channel seismic imaging of a crustal magma chamber along the East Pacific Rise. Nature 326, 35-41 (1987).

3 Herron, T. J. et al., Structure of the East Pacific Rise crest from multichannel seismic reflection data. J. Geophys. Res. 83, 798-804 (1978).

4 Karson, J. A., Geologic structure of the uppermost oceanic crust created at fastto intermediate-rate spreading centers. Annual Review of Earth and Planetary Science 30, 347-384 (2002).

5 Perfit, M. R. and Chadwick, W. W., Magmatism at mid-ocean ridges: Constraints from volcanological and geochemical investigations. In Faulting and Magmatism at Mid-Ocean Ridges, edited by W. R. Buck, P. T. Delaney, J. A. Karson et al. (AGU, Washington, D. C., 1998), Vol. 106, pp. 59-115.

6 Sinton, J. M. and Detrick, R. S., Mid-ocean ridge magma chambers. J. Geophys. Res. 97, 197-216 (1992).

7 Maclennan, J., Hulme, T., and Singh, S. C., Thermal models of oceanic crustal accretion: Linking geophysical, geological and petrological observations. Geochem., Geophys., Geosyst. 5, Q02F25, doi:10.1029/2003GC000605 (2004). 
Kelemen, P. B., Koga, K., and Shimizu, N., Geochemistry of gabbro sills in the crust-mantle transition zone of the Oman ophiolite: Implications for the origin of the oceanic lower crust. Earth Planet. Sci. Lett. 146, 475-488 (1997).

9 Boudier, F., Nicolas, A., and Ildefonse, B., Magma chambers in the Oman ophiolite: fed from the top and the bottom. Earth Planet. Sci. Lett. 144, 239-250 (1996).

10 Kelemen, P. B. and Aharonov, E., Periodic formation of magma fractures and generation of layered gabbros in the lower crust beneath oceanic spreading ridges. In Faulting and Magmatism at Mid-Ocean Ridges, edited by W. R. Buck, P. T. Delaney, J. A. Karson et al. (AGU, Washington, D.C., 1998), Vol. 106, pp. 267-289.

11 Korenaga, J. and Kelemen, P. B., Origin of gabbro sills in the Moho transition zone of the Oman ophiolite: Implications for magma transport in the oceanic lower crust. J. Geophys. Res. 102, 27,729-27,749 (1997).

12 Singh, S. C. et al., Seismic reflection images of the Moho underlying melt sills at the East Pacific Rise. Nature 442, doi:10.1038/nature04939 (2006).

13 Crawford, W. C. and Webb, S. C., Variations in the distribution of magma in the lower crust and at the Moho beneath the East Pacific Rise at $9^{\circ}-10^{\circ}$ N. Earth Planet. Sci. Lett. 203, 117-130 (2002).

14 Dunn, R. A., Toomey, D. R., and Solomon, S. C., Three-dimensional seismic structure and physical properties of the crust and shallow mantle beneath the East Pacific Rise at $9^{\circ} 30^{\prime}$ N. J. Geophys. Res. 105, 23,537-23,555 (2000).

15 Garmany, J., Accumulations of melt at the base of young oceanic crust. Nature 340, 628-632 (1989).

16 Wilcock, W. S. D., Solomon, S. C., Purdy, G. M., and Toomey, D. R., The seismic attenuation structure of a fast-spreading mid-ocean ridge. Science 258, 14701474 (1992). 
Mutter, J. C. et al., Seismic images of active magma systems beneath the East Pacific Rise between $17^{\circ} 05^{\prime}$ and $17^{\circ} 35^{\prime}$ S. Science 268, 391-395 (1995).

18 Singh, S. C. et al., Melt to mush variations in crustal magma properties along the ridge crest at the southern East Pacific Rise. Nature 394, 874-878 (1998).

19 Nedimović, M. R. et al., Frozen magma lenses below the oceanic crust. Nature, 1149-1152 (2005).

20 Wilson, D. S., Confidence intervals for motion and deformation of the Juan de Fuca plate. J. Geophys. Res. 98, 16,053-16,071 (1993).

21 Canales, J. P. et al., Upper crustal structure and axial topography at intermediate-spreading ridges: seismic constraints from the Southern Juan de Fuca Ridge. J. Geophys. Res., B12104, doi:10.1029/2005JB003630 (2005).

22 Carbotte, S. M. et al., Rift topography linked to magmatism at the intermediate spreading Juan de Fuca Ridge. Geology 34, 209-212 (2006).

23 Jousselin, D. and Nicolas, A., The Moho transition in the Oman ophiolite relation with wherlites in the crust and dunites in the mantle. Mar. Geophys. Res. 21, 229-241 (2000).

24 Taylor, M. A. J. and Singh, S. C., Compositions and microstructure of magma bodies from effective medium theory. Geophys. J. Int. 149, 15-21 (2002).

25 Aharonov, E., Whitehead, J., Kelemen, P. B., and Spiegelman, M., Channeling instability of upwelling melt in the mantle. J. Geophys. Res. 100, 20433-20450 (1995).

26 Kelemen, P. B., Shimizu, N., and Salters, V. J. M., Extraction of mid-ocean ridge basalt from the upwelling mantle by focused flow of melt in dunite channels. Nature 375, 747-753 (1995). 
Korenaga, J. and Kelemen, P. B., Melt migration through the oceanic lower crust: a constraint from melt percolation modeling with finite solid diffusion. Earth Planet. Sci. Lett. 156, 1-11 (1998).

28 Hooft, E. and Detrick, R. S., The role of density in the accumulation of basaltic melts at mid-ocean ridges. Geophys. Res. Lett. 20, 423-426 (1993).

29 Phipps Morgan, J. and Chen, Y. J., The genesis of oceanic crust: Magma injection, hydrothermal circulation, and crustal flow. J. Geophys. Res. 98, 6283-6297 (1993).

30 Stakes, D. S. et al., The Cleft revealed: Geologic, magnetic, and morphologic evidence for construction of upper oceanic crust along the southern Juan de Fuca Ridge. Geochem., Geophys., Geosyst. 7, Q04003, doi:10.1029/2005GC001038 (2006).

31 Barth, G. A. and Mutter, J. C., Variability in oceanic crustal thickness and structure: Multichannel seismic reflection results from the northern East Pacific Rise. $J$. Geophys. Res. 101, 17,951-17,975 (1996).

32 Dilek, Y., Moores, E. M., and Furnes, H., Structure of modern oceanic crust and ophiolites and implications for faulting and magmatism at oceanic spreading centers. In Faulting and magmatism at mid-ocean ridges, edited by W. R. Buck, P. T. Delaney, J. A. Karson et al. (AGU, Washington D. C., 1998), Vol. 106, pp. 153-176. 33 Coogan, L. A. et al., Petrology and geochemistry of the lower ocean crust formed at the East Pacific Rise and exposed at Hess Deep: A synthesis and new results. Geochem., Geophys., Geosyst. 3, 8604, doi:10.1029/2001GC000230 (2002).

Supplementary Information is linked to the online version of the paper at www.nature.com/nature.

Acknowledgements This research was supported by grants form the US NSF. We thank the captain, crew and scientific party of RV Maurice Ewing Cruise 0207. 
Author Contributions All authors participated in the data acquisition experiment. J.P.C. processed the data, interpreted them, and wrote the paper with contributions from all of the co-authors.

Author Information Reprints and permissions information is available at www.nature.com/reprints. The authors declare no competing financial interests. Correspondence and requests for materials should be addressed to J.P.C. (jpcanales@whoi.edu).

Figure 1 | Seismic reflection profiles located over a bathymetric map of the Cleft segment of the southern Juan de Fuca Ridge. Colours represent seafloor depth in meters, with contours every $100 \mathrm{~m}$. Numbered solid lines are seismic profiles shown in Figs. 2 and 4. Dashed line locates the spreading axis. Yellow lines locate the plan-view extent of the LCML reflection event shown in Figs. 2 and 4 . Thick grey lines locate sub-Moho reflection events identified by ${ }^{19}$ in the vicinity of Cleft segment. Red triangle locates low-temperature hydrothermal vents observed on the seafloor ${ }^{30}$. Top-right inset shows location of the study area in the Northeast Pacific. Names indicate tectonic plates; arrows indicate direction of seafloor spreading.

Figure 2 | Migrated seismic reflection profiles $\mathbf{4 0}$ and 75. a. Ridge-parallel profile 40 is located $3.3 \mathrm{~km}$ to the east of the spreading axis (Fig. 1). Vertical line locates the intersection with profile 75 . Boxes enclose parts of the profile shown in detail in c, d, and e. Red triangle locates low-temperature hydrothermal vents observed on the seafloor ${ }^{30}$. b. Ridge-perpendicular profile 75. Vertical line locates the intersection with profile 40 . Spreading axis is within the labelled axial graben. Boxes enclose parts of the profile shown in detail in $f$ and g. Main events are indicated with colour arrows: top of axial magma chamber (AMC), lower crustal melt sill (LCML), and Moho (M). Vertical axes are two-way travel time in seconds for all panels. Scale bar in the middle is for panels c-g. Locations of CMP 12420 (Fig. 3a) and 9510 (Fig. 3b) are labelled in 
$c$ and $d$, respectively. The event labelled as sideswipe in $d$ is interpreted as such based on its steep hyperbolic diffraction character observed in the stacked image (Supplementary Fig. S2a, d), as well as in its higher frequency content relative to the lower-frequency, flat-lying Moho events. Unmigrated stack versions of the images shown here are presented in Supplementary Fig. S2.

Figure 3 | Observed and modelled reflection amplitudes and travel times.

a. CMP supergathers 12420 and b. 9510 from profile 40 (see locations in Fig. 2c, d). $P$ waves reflecting off the Moho and the LCML $\left(P_{L C M L} P\right)$ are indicated. Weak but coherent arrivals are observed in CMP 9510 at $\sim 4.0-5.5 \mathrm{~km}$ offset between $\sim 5.5-5.6 \mathrm{~s}$, and at far offsets $(>4.5 \mathrm{~km})$ between $\sim 6.0$ and $6.2 \mathrm{~s}$, and are tentatively interpreted as Moho reflections and S-converted waves reflecting off the LCML $\left(P_{L C M L} S\right)$, respectively. (The $P_{L C M L} S$ would be converted back to $P$ at the seafloor to be detected by the hydrophone streamer.) c. Predicted travel time curves for Moho reflection, $P_{L C M L} P$ and $P_{L C M L} S$ (see Methods). d. Instantaneous amplitude of CMP supergathers 12420 and e. CMP 9510 within a 1-s window around the Moho and $P_{L C M L} P$ arrivals, respectively (see Methods). f. AVO analysis of Moho and $P_{L C M L} P$ events (green and black lines, respectively); amplitude scale at left vertical axis. The instantaneous amplitudes versus offset at a constant time of 5.445 s for CMP 12420, and 5.075 s for CMP 9510 (short thick lines in $\mathbf{d}$ and $\mathbf{e}$, respectively) are shown as thin solid lines. Thick solid lines correspond to least-squares cubic fits (dashed lines are $50 \%$ confidence limits of the polynomial fits). The increase in instantaneous amplitude for CMP 9510 at offsets $>5 \mathrm{~km}$ is due to interference of high-amplitude, steeply-dipping seafloor reflections and diffractions with the $P_{L C M L} P$ event, and it does not accurately represent the AVO response of this event. Predicted $P$-wave reflection coefficients versus source-receiver offset (amplitude scale at right vertical axis) are shown for two scenarios (see Methods): the lower medium is a 
molten sill (short dashed black line, labelled "melt"), or it represents mantle or a solid ultramafic sill (short dashed green line, labelled "ultramafic"). Horizontal axes in all panels are source-receiver offset.

Figure 4 | Three-dimensional perspective of crustal structure and seafloor topography. a. Southern and eastern parts of profiles 40 and 75 , respectively, are shown hanging from the seafloor topography. Moho and LCML events identified in Fig. 2 are emphasized with colour markers. White dashed line locates the spreading axis. SM is a young-looking, near-axis seamount with chemistry distinct from the axial lava flows ${ }^{30}$. Red triangle locates lowtemperature hydrothermal vents observed on the seafloor ${ }^{30}$. Solid lines locate profiles shown in b. b. Profile 80 , northern part of profile 40 , and central section of profile 75 , all shown hanging from the seafloor topography. Moho, LCML, and AMC events identified in Fig. 2 are emphasized with colour markers. White dashed line locates the spreading axis, which is coincident with profile 80.

\section{METHODS}

Traveltime curves. Traveltime curves were calculated assuming a one-dimensional model consisting of a 2319-m-thick water layer $\left(V_{P}=1500 \mathrm{~m} \mathrm{~s}^{-1}\right)$, a 5940-m-thick crustal layer above the LCML $\left(V_{P}=6000 \mathrm{~m} \mathrm{~s}^{-1}\right)$, and a 1000-m-thick layer between the LCML and the Moho $\left(V_{P}=5000 \mathrm{~m} \mathrm{~s}^{-1}\right)$. Crustal Poisson's ratio is 0.25 .

Reflection coefficients. Reflection coefficients were calculated by assuming two homogeneous, semi-infinite media separated by a flat interface. We considered two models with the same upper medium properties but different lower medium properties. For the upper medium representing the gabbroic lower crust we use the following elastic parameters: $V_{P}=6500 \mathrm{~m} \mathrm{~s}^{-1}, V_{S}=3550 \mathrm{~m} \mathrm{~s}^{-1}, \rho=2800 \mathrm{~kg} \mathrm{~m}^{-3}$. These parameters represent average laboratory measurements made at room temperature and $200 \mathrm{MPa}$ 
confining pressure in gabbros drilled at the Mid-Atlantic Ridge ${ }^{34}$ after correcting for the expected elevated temperatures of the near-axis lower crust $\left(900{ }^{\circ} \mathrm{C}[7]\right)$, assuming that $V_{P}$ decreases with temperature as $-0.57 \times 10^{-3} \mathrm{~km} \mathrm{~s}^{-1} \mathrm{~K}^{-1}[35]$ and a Poisson's ratio of 0.29 $[34,36]$.

In the first model the lower medium represents a melt sill. We use the definition of ${ }^{18}$ : melt refers to liquid matrix with disconnected crystals, with $V_{s} \approx 0 \mathrm{~km} \mathrm{~s}^{-1}$. We use the following elastic parameters: $V_{P}=3400 \mathrm{~m} \mathrm{~s}^{-1}{ }^{[18]}, V_{S}=0 \mathrm{~m} \mathrm{~s}^{-1}, \rho=2700 \mathrm{~kg} \mathrm{~m}^{-3}{ }^{[28]}$.

In the second model the lower medium represents ultramafic rocks. We use the following elastic parameters: $V_{P}=7700 \mathrm{~m} \mathrm{~s}^{-1}, V_{S}=4400 \mathrm{~m} \mathrm{~s}^{-1}, \rho=3200 \mathrm{~kg} \mathrm{~m}^{-3}$. These parameters represent average values for Wehrlite and Harzburgite compositions ${ }^{37}$ after correcting for the expected elevated temperatures of the near-axis lower crust $\left(900{ }^{\circ} \mathrm{C}\right.$ ${ }^{[7]}$ ), assuming that $V_{P}$ decreases with temperature as $-0.54 \times 10^{-3} \mathrm{~km} \mathrm{~s}^{-1} \mathrm{~K}^{-1}[35]$ and a Poisson's ratio of $0.26^{[36]}$.

The predicted reflection coefficients do not exactly reproduce the observed AVO responses because the simplified models do not include effects such as energy attenuation and cannot fully describe complex reflectivity. True reflection coefficients for the LCML and Moho could not be estimated from the seafloor multiple-to-primary amplitude ratio due to seafloor diffractions that interfere with the LCML at zero-offset.

34 Miller, D. J. and Christensen, N. I., Seismic velocities of lower crustal and upper mantle rocks from the slow spreading Mid-Atlantic Ridge, south of the Kane transform zone (MARK). Proc. ODP Sci. Res. 153, 437-454 (1997).

35 Christensen, N. I., Compressional wave velocities in rocks at high temperatures and pressures, critical thermal gradients, and crustal low-velocity zones. J. Geophys. Res. 84, 6849-6857 (1979). 
Christensen, N. I., Poisson's ratio and crustal seismology. J. Geophys. Res. 101, 3139-3156 (1996).

37 Karson, J. A., Collins, J. A., and Casey, J. F., Geologic and seismic velocity structure of the crust/mantle transition in the Bay of Islands ophiolite complex. $J$. Geophys. Res. 89, 6126-6138 (1984). 


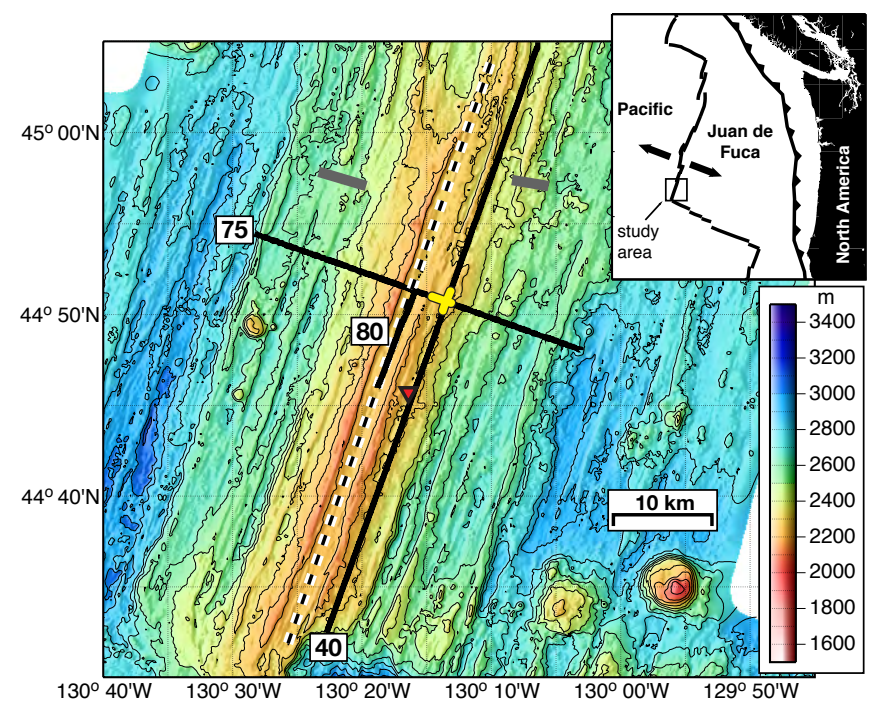



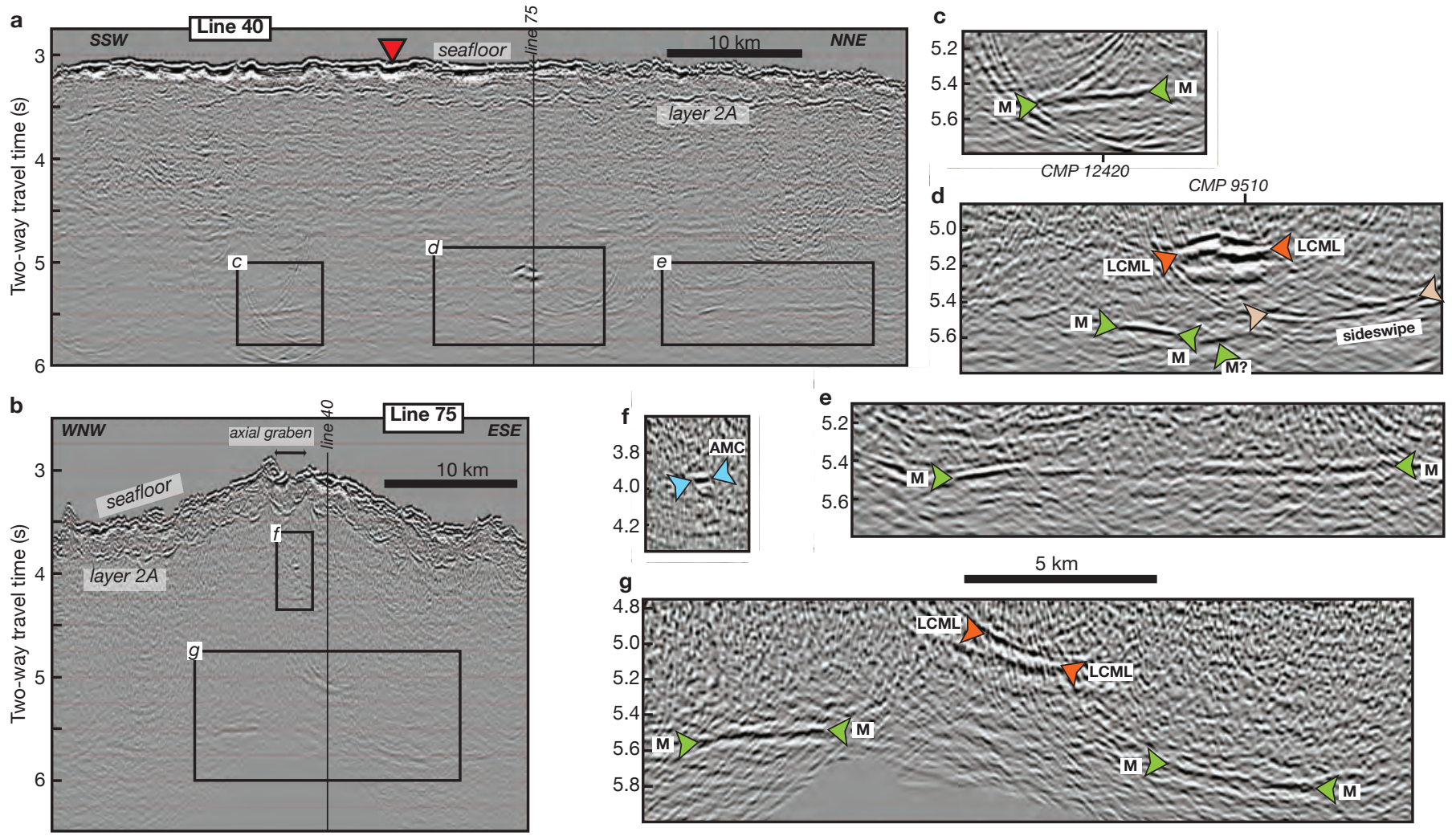


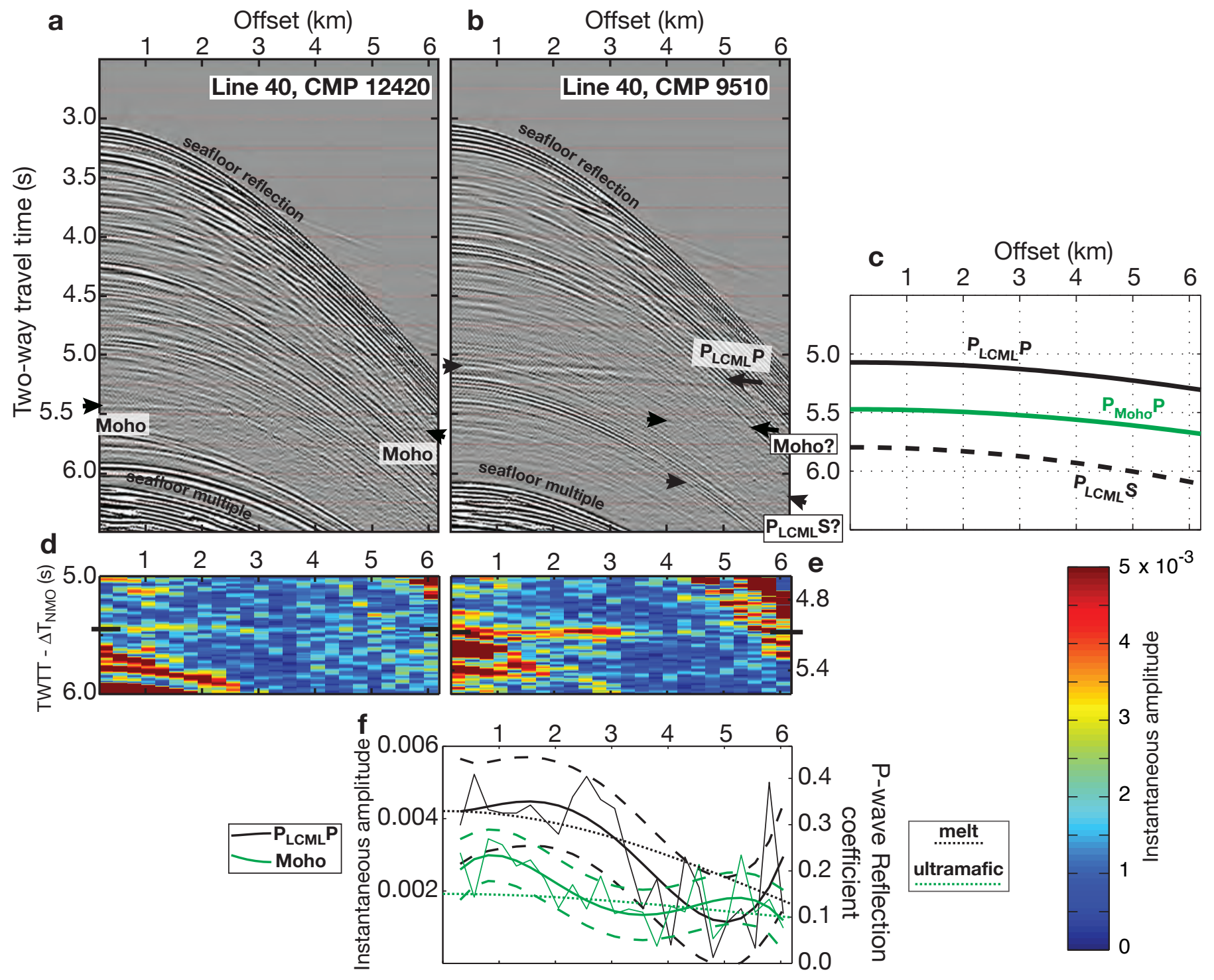




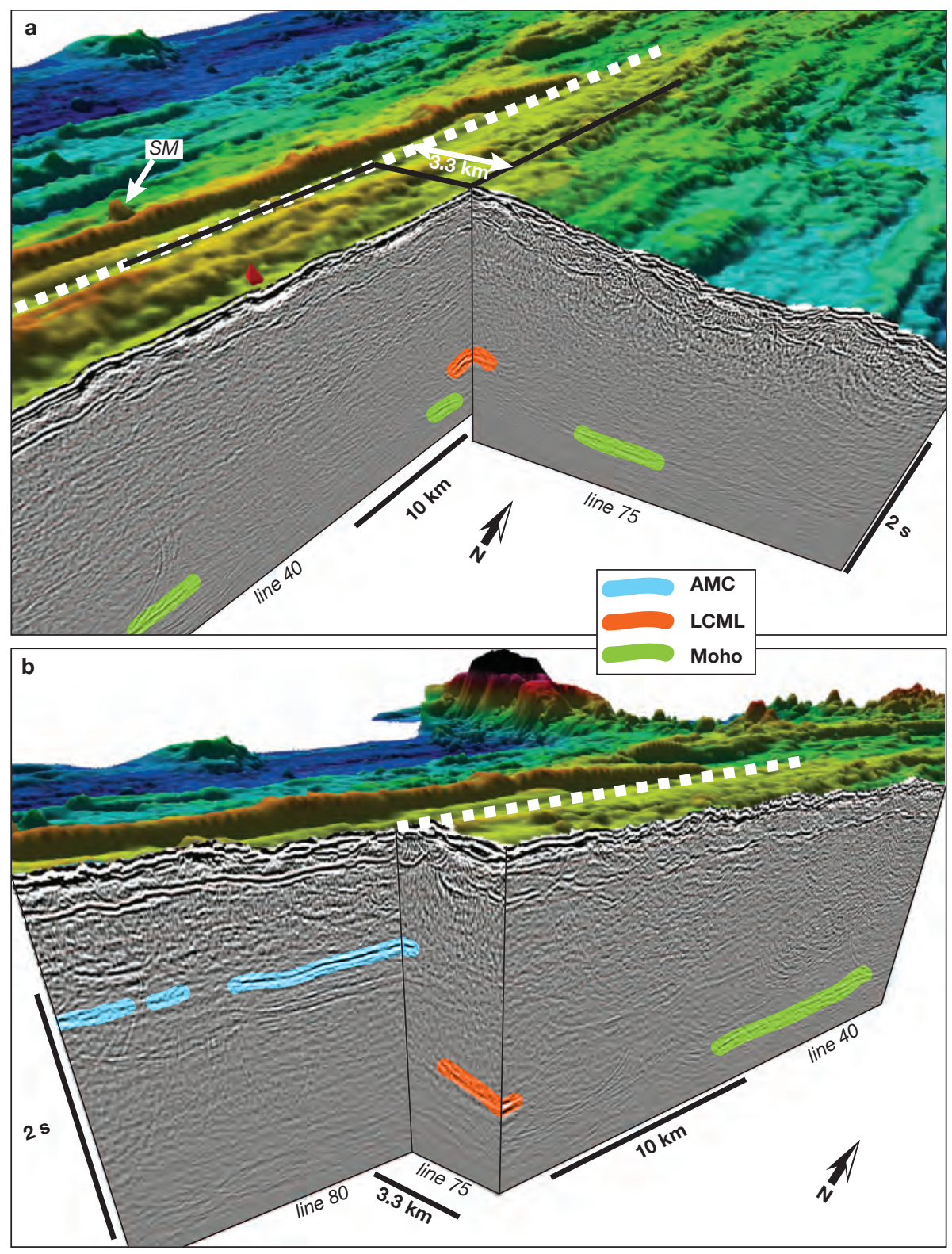




\section{SUPPLEMENTARY INFORMATION}
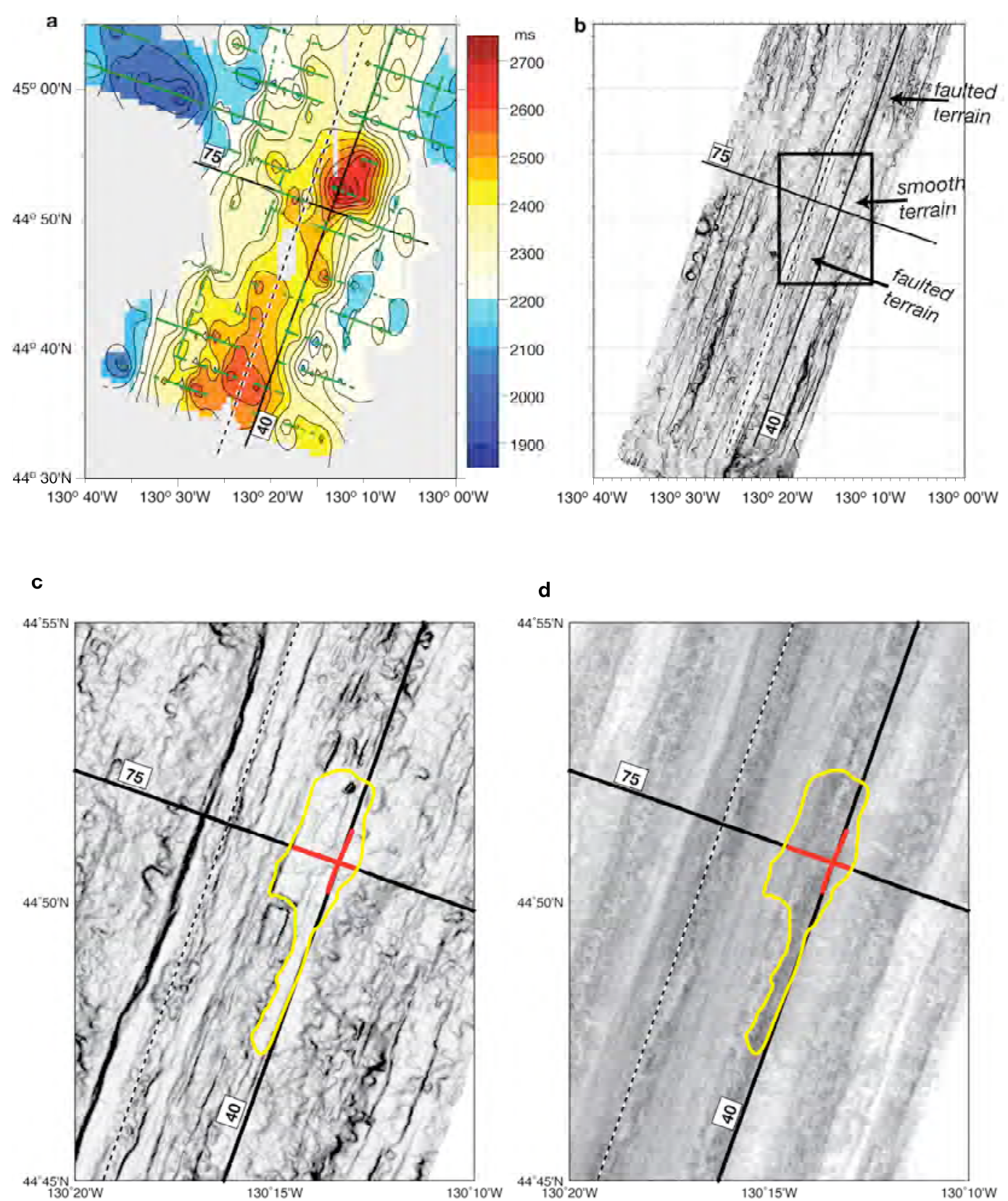

Figure S1. a. Map of seafloor-to-Moho two-way traveltime (color scale in milliseconds to the right) derived from all of the EW0207 seismic profiles available in the area ${ }^{21}$. Green dots are locations where Moho was identified and picked; data points were interpolated onto a regular grid using a minimumcurvature algorithm. Contours are every $50 \mathrm{~ms}$. Black lines are seismic profiles 75 and 40 ; dashed line is the ridge axis. b. Seafloor slope map of Cleft segment derived from high-resolution EM-300 multibeam bathymetry ${ }^{30}$. Light gray shading corresponds to sub-horizontal terrain and dark shading to slopes higher than 20 degrees. Box corresponds to area shown in b and c. Other lines are as in (a). Details of seafloor slope (c) and EM-300 seafloor backscatter (i.e., reflectivity) (d) near the intersection of profiles 75 and 40 (black lines). Red lines indicate the plan-view extent of the LCML reflection event shown in Figs. 2 and 4. Yellow line encloses area of the seafloor where seafloor reflectivity is higher (darker) than the surrounding seafloor. 

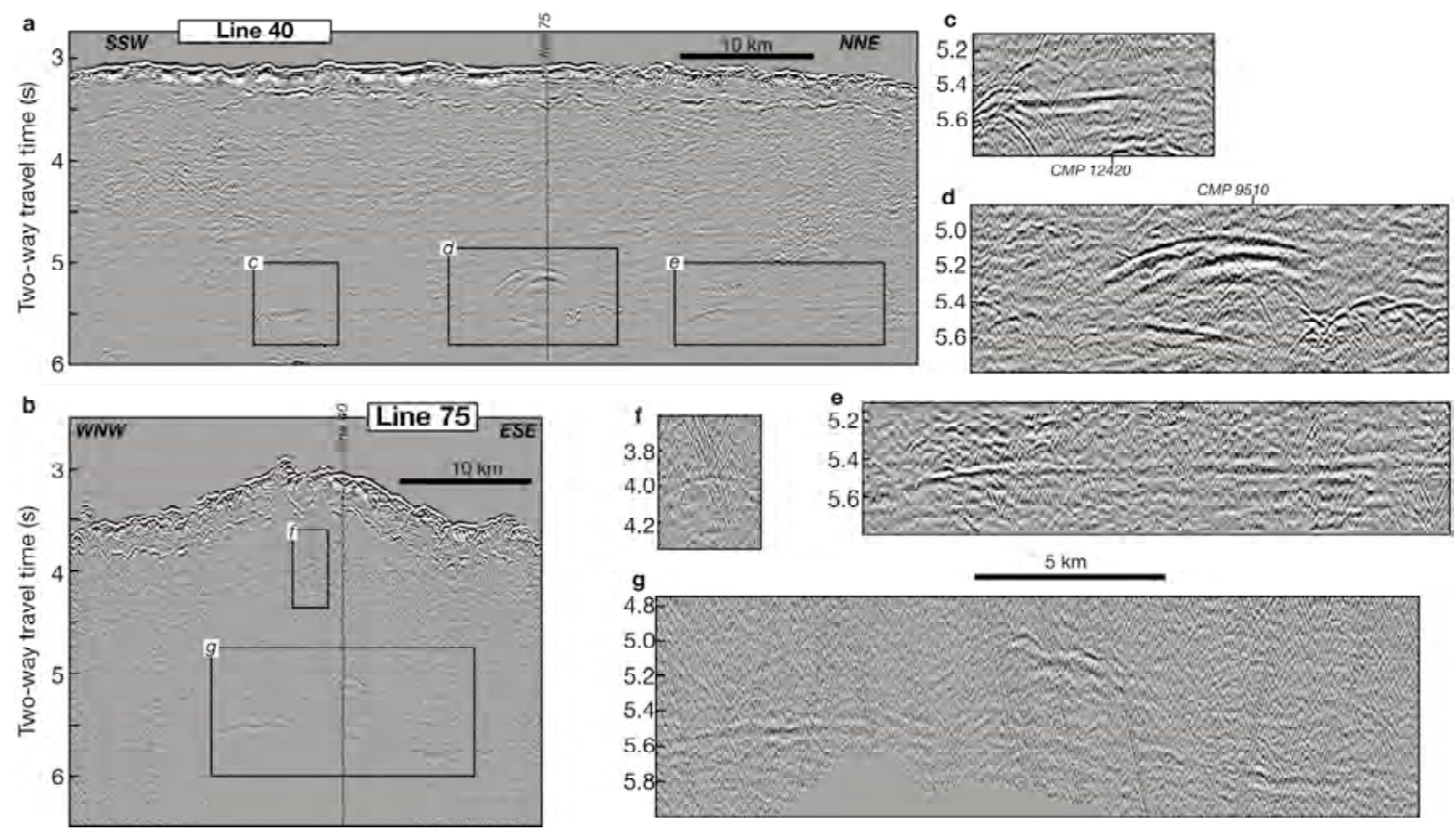

Figure S2. Unmigrated stacks of reflection profiles shown in Fig. 2 without interpretation. Processing steps are indicated in the Methods section.

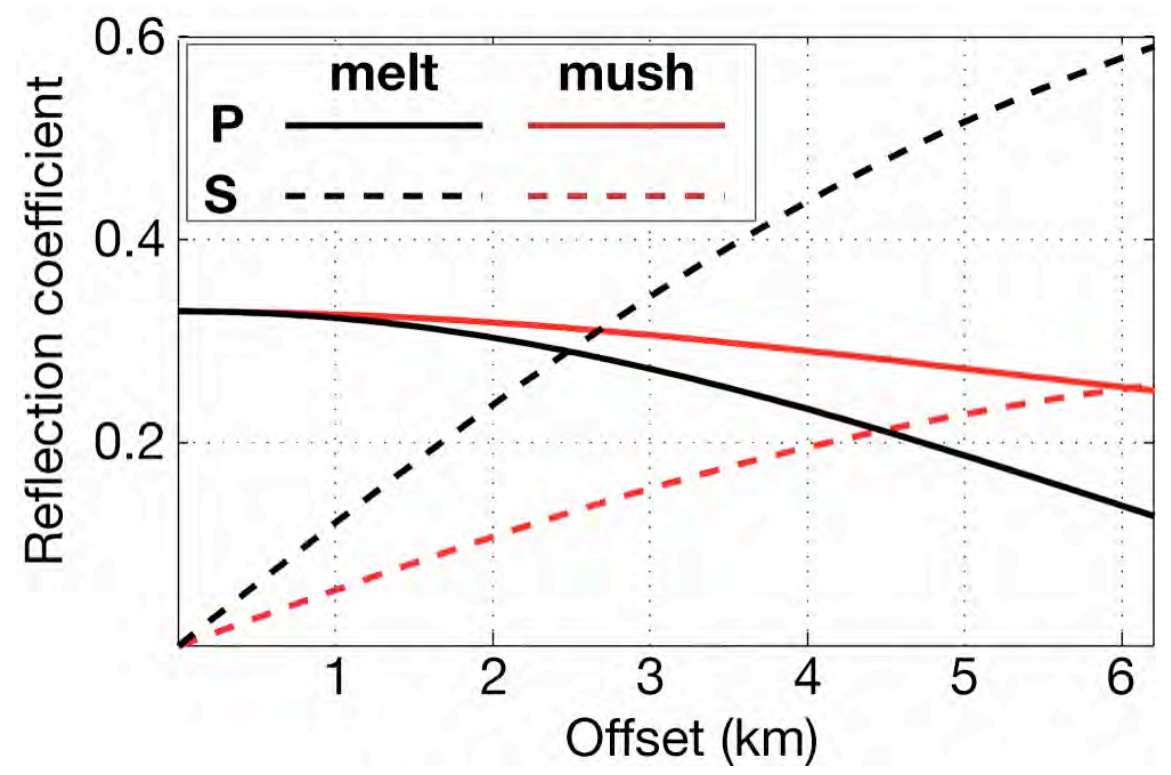

Figure S3. Predicted reflection coefficients versus source-receiver offset for $P_{L C M L} P$ (solid lines) and $P_{L C M L} S$ (dashed lines) for the "melt" model described in Fig. 3 and Methods section (black lines), and a partially-crystallized sill model ("mush", red lines: $V_{P}=3400 \mathrm{~m} \mathrm{~s}^{-1}, V_{S}=3200 \mathrm{~m} \mathrm{~s}^{-1}, \rho=2700 \mathrm{~kg} \mathrm{~m}^{-3}$ ). The $P_{L C M L} S$ is predicted to have maximum amplitudes at offsets of 10-12 km (not shown in here), beyond the maximum offset of our data $(6.2 \mathrm{~km})$. Horizontal axis is source-receiver offset. 